\title{
RAÍZES E IDENTIDADE DE MIGRANTES TRABALHADORES rurais do Centro-Sul no ACre: uma análise a Partir DA LINGUAGEM METAFÓRICA
}

\section{Tânia Mara Rezende Machado ${ }^{1}$}

RESUMO: A linguagem é um dos principais símbolos de uma cultura. Sem linguagem não há possibilidade de definição de identidades, de território de pertencimento, de análise das relações de trabalho, de processos de desenraizamentos, enraizamentos, reenraizamentos de um povo e principalmente, do estabelecimento de comunicação entre povos. Embora hoje exista um encurtamento de fronteiras pela ampliação das formas de comunicação advindas da globalização, esse encurtamento ocorre de modo distinto a depender da classe social a que as pessoas pertencem. Com este artigo têm-se o objetivo de analisar as raízes e identidades de migrantes trabalhadores rurais do centro-sul no Acre, evidenciadas por meio de metáforas, reforçando assim, o valor literário e linguístico destas para a preservação da memória e identidade. O estudo enquadra-se nos estudos culturais tal como pensados por Williams (1979) e Thompson (1998).

Palavras-chave: Migrantes. Trabalhadores Rurais. Identidades. Linguagem.

\section{Considerações iniciais}

Eu sou como Apui, não tem vento que me leve, nem chuva que me derrube. Minhas raiz vai longe por esse chão afora.

(Miguel Alves Rodrigues)

A linguagem é um dos principais símbolos de uma cultura. Sem linguagem não há possibilidade de definição de identidades, de território de pertencimento, de análise das relações de trabalho, de processos de desenraizamentos, enraizamentos, reenraizamentos, e, principalmente, do estabelecimento de comunicação entre povos. Neste sentido, a linguagem apresenta-se como componente imprescindível às análises que se pretendam ser de natureza cultural. Contudo, na contramão desses estudos, os discursos sobre os processos migratórios de globalização tendem a advogar o encurtamento de fronteiras propiciado

\footnotetext{
${ }^{1}$ Doutora em Educação, Professora da Universidade Federal do Acre.
} 
pela ampliação das formas de comunicação advindas das múltiplas linguagens que emergem de tal processo. Porém, é bom refletir a respeito do alcance social desse encurtamento de fronteiras. Para alunos oriundos das classes dominantes é provável que as fronteiras sejam encurtadas, pois estes têm acesso à internet, bons filmes, livros, músicas, jornais, documentários, fotografias, diálogos em família, que se pautam nos códigos formais da língua materna e, em alguns casos, em uma segunda língua. Já para os alunos das classes menos favorecidas, sobralhes a linguagem das águas, dos rios, das secas e enchentes catastróficas, das luas e principalmente, de uma oralidade carregada de metáforas e cacófatos.

Nessa direção, procurando dialogar com essas questões, partimos da noção de cultura a partir da compreensão de Thompson que a define como um

termo emaranhado, que ao reunir tantas atividades e atributos em um só feixe pode na verdade confundir ou ocultar distinções que precisam ser feitas. Será necessário desfazer o feixe e examinar com mais cuidado os seus componentes (THOMPSON, 1998, p.22).

Para "desfazer este feixe e examinar com mais cuidado seus componentes", neste estudo trazemos para análise as raízes e identidade de migrantes trabalhadores rurais do centro-sul no Acre, evidenciadas por meio do uso de metáforas presentes em seus depoimentos e falas, interpretadas teoricamente com base em Santos (1999) e Nascimento (1985).

Quanto às justificativas para o uso da linguagem metaforizada tomada de empréstimo de trabalhadores rurais sujeitos dessa pesquisa, explica-se pelo fato de que, em seus cotidianos, involuntariamente, tendem a dispor de metáforas ou comparações para se comunicar.

O uso de metáforas compreende "espaço de liberdade ao subverter as regras da língua para inscrever sua subjetividade criativa” (ZANOTTO, 1985, p. 132). Isto implica em dizer que elas são produzidas em contextos situados e guardam consigo as marcas culturais de seus criadores. Nesse sentido, torna-se difícil definir o que seja metáfora, posto que sua definição depende, em grande parte, da diversidade de pontos de vista teóricos existentes nesse domínio, 
bem como da complexidade do fenômeno em si. A depender da tradição cultural, da época e do teórico em que a metáfora é utilizada pode mudar seus limites, sua forma e seu sentido. Cumpre-nos ressaltar, no entanto, que, neste estudo, as metáforas analisadas correspondem às expressões comunicativas de trabalhadores rurais que vivem em Projetos de Assentamento Dirigidos, do Instituto Nacional de Reforma Agrária - INCRA.

Compete-nos também, explicitar que Daniel Francisco dos Santos, que escreveu sobre garimpeiros em Rondônia, e Heloisa Winter Nascimento cuja dissertação de mestrado teve como título "Rumo da terra: rumo da liberdade. Um estudo dos migrantes rurais do sul no estado do Acre", defendida em 1985, foram nossos primeiros interlocutores para tratar de desenraizamento, enraizamento, reenraizamento de migrantes.

Nos escritos desses autores, que não trabalham sozinhos ou sem bases empíricas, evidencia-se uma lógica de que migrar é sinônimo de perda de identidades, contudo, se analisarmos as falas e os escritos de alguns migrantes, observaremos que os mesmos não são pessoas desenraizadas, mas, sujeitos portadores de culturas plurais e, portanto, de identidades constituídas nas mais diversas dimensões de seus modos de viver, que por vezes se conformam, por vezes resistem e, em diversos momentos, suas formas de resistência e conformismo se camuflam.

\section{O diálogo metafórico travado com os sujeitos da pesquisa}

Nesta parte do texto trazemos um diálogo metafórico travado com alguns sujeitos da pesquisa. Trata-se de vozes de homens e mulheres ávidos por exporem suas ideias sobre raízes e identidades, ainda que desconheçam formalmente esses conceitos.

Nossa primeira interlocutora foi a senhora Inês S. Espindola, residente no Projeto Humaitá, na Amazônia acreana, que ao ser questionada sobre como se sentiu por ocasião de sua chegada ao Acre diz: "Nois era cumu assim uma laranjera que rancaru do chão. As raiz quebraro tudo e então custa a ela pegá de novo. Mais nóis tá pelejano. Se aumeno meu pai tivesse vindo mais eu" (ESPINDOLA, 2000). 
A partir da narrativa da depoente, é possível afirmar que, por um tempo que não é permanente, o migrante se sente como se estivesse perdido suas raízes. O que não significa dizer que isso seja algo natural, que vá passar com o tempo, que ele abandonará os vínculos com suas origens. Quando uma raiz quebra, outras surgem, galhos brotam, folhas nascem, mas o tronco, "a árvore", a espécie permanece, manifestando suas práticas e modos de ser.

Em sua fala, a expressão "se aumeno meu pai tivesse vindo mais eu", significa que as raízes não foram esquecidas, pois estavam fazendo falta, causando saudades. O manejo florestal pelo qual somente é retirada uma árvore se esta tiver filhas e netas da mesma espécie que a substitua no futuro não funciona de forma semelhante aos laços familiares de migrantes. É bastante recorrente nas falas desses migrantes o desejo de estar próximo aos familiares, propiciando seus deslocamentos para o Acre. Ocorre também, de quando possível, retornarem ao local de origem para rever parentes ou para levar os filhos para conhecer o lugar de onde partiram. Vejamos o depoimento do senhor Hélio Tessinari, migrante do Espírito Santo, descrevendo o momento de reencontro com as raízes.

Aí dessa última veiz que eu fui, levei o filho moço, sabe? O Ronaldo. Cheguei lá eu falei: vô te levá no lugar onde você nasceu. Milagre! Tinha... pur sinal tinha até uma festinha lá nesse lugar, um dia de dumingo. Aí no meio da festinha, eu via qui ele saía prum cantu, olhava aquelas pedras qui iam lá no alto, in cima, aí ele disse: "Papai, mais eu nasci aqui?” Eu disse: "nasceu. Tú voltaria pra cá? Ele disse: "nem se mi desse isso tudo duma vez". Não, mais é isquisito mesmo. Parece aquelas pedras de um lado assim, parece qui juntaru mais. Purquê aqui a gente, vive assim nesse mundo ispaçoso assim. Lá, cê olha prum lado, cê vai cem metro isbarra numa pedra qui vai lá in cima, vai isbarra quase, vai isbarrara quase na flô do céu (TESSINARI, 2000).

Ainda que o lugar de origem possa parecer estranho e não propicie o desejo de voltar a residir nele, a preocupação com o retorno às raízes, ainda que periodicamente está presente nas famílias migradas para o Acre.

Querer unificar identidades, tempos e espaços tem sido o desejo de muitos. Embora tenhamos a compreensão da importância de estudos 
que tratem das questões regionais, a história acreana, veiculada por meio das múltiplas linguagens, sejam elas musicais, poéticas, religiosas, literárias e outras, trazem embutidas valores por vezes estereotipados que podem funcionar como elementos de sedimentação de representações. Especialmente a história produzida durante os denominados anos de governo da Frente Popular do Acre.

Nessa direção, recorremos à fala de outro migrante, citado por Eloísa Winter, referindo-se ao padrão de vida que estava levando aqui e o que tinha no sul: "Fazê o que? Pra todo lado que corre o urubú é preto. Intão não tem jeito, tem que ficá” (NASCIMENTO, 1985, p. 144). A partir dessas considerações, chamamos a atenção para uma reflexão que está presente ao longo de todo este estudo, qual seja: a quem interessa unificar identidades? Será que a expressão metaforiada de que "urubu é preto em todo lugar" não merece uma melhor análise? Urubu pode até ser preto em todo lugar, mas não em todo tempo. Quando é novo, é branco!

Deixando as metáforas de lado por um momento e acompanhando a linguagem expressa em algumas cartas escritas por migrantes trabalhadores rurais provenientes de Brasilândia, no estado do Paraná e Amambaí, no estado do Mato Grosso do Sul, vejamos onde estão seus corações, suas raízes. A carta abaixo, escrita por José Padilha da Silva, professor e trabalhador rural migrante de Brasilândia, expressa um pouco do seu viver no Acre e as saudades que sente dos familiares e da terra de onde partiu.

Sena Madureira-Acre, 30/07/2001.

Saudações.

Meu querido primo, Fabiano, estou te escrevendo para dar-te as minhas notícias, desejando que esta vai te encontrar gozando perfeita saúde.

Primo faz 29 anos que estou morando aqui no Estado do Acre mas ainda não me esqueci de você e nem dos meus amigos que ai deixei. Primo quando nós chegamos aqui nós fomos trabalhar em uma fazenda somente após estes anos é que meu pai ganhou um lote de terra em um assentamento do INCRA denominado Projeto Boa Esperança, a partir daí muitas coisas tivemos que aprender com os acreanos. Aprendemos a cortar seringa, aprendemos a quebrar castanha com tersado, 
aprendemos a amansar bois para transportes, aprendemos a chamar fumo de tabaco e em fim quase todas as coisas aqui são diferentes das nossas aí. Mas apesar das dificuldades aqui é um lugar bom para viver.

Primo, hoje eu sou casado com uma acreana, tenho um lote de terra, sou professor rural, estou fazendo o Pró -Formação e tudo que tenho consegui no Acre, mas não me esqueci de minha terra natal. Fabiano, sinto muita saudade da escola que eu estudei, daquele lindo plantio de trigo próximo da escola, daquele plantio de algodão; há! Primo que saudade de Brasilândia onde meu pai fazia compras. Sei que com o auxílio de Deus um dia irei visitá-los. Primo vou me despedindo com muita saudade, aguardando uma carta sua. Um forte abraço de seu primo e amigo José Padilha da Silva.

Primo me escreva por este endereço:

Sena Madureira-Acre. CEP 69.940-000.

Nessa carta, José Padilha da Silva faz uma retrospectiva do seu viver no Acre, fala dos anos em que seu pai trabalhou para fazendeiro e da conquista da terra própria. Conta das dificuldades enfrentadas e das aprendizagens quer teve junto ao povo acreano. Informa que casou e que está estudando. Em suas palavras fica nítida sua satisfação com o viver no Acre quando diz "tudo que tenho consegui no Acre". Contudo, sente saudades do primo e da cidade de Brasilândia. Relembra ainda, dos plantios de trigo e de algodão que havia próximo à escola onde estudara. Mostrando que não é um desenraizado, mas que apenas criou novas raízes no Acre. É, portanto, um reenraizado.

As cartas seguintes foram escritas pela migrante Eva dos Santos Cardoso, escritas em tempos diferentes. Uma em 1976 e outra em 2000, para a irmã Neuza que reside em Amambaí. Lendo as duas cartas é possível perceber que mesmo tendo transcorrido vinte e quatro anos entre a escrita de uma e da outra, a saudade é um elemento presente que somente sente quem tem raiz.

Sena Madureira, 02 de fevereiro de 1976.

Querida irmã Neuza,

To te escreveno cum muita tristeza prá contá que a tia Ana 
morreu. O médico já tinha falado que quando desse derrame dinovo ela murria. A mãe tá sofreno por causa que a tia Ana era a única irmã que ela tinha viva.

Neuza eu vo mora na cidade mais dona Maria. Se de certo eu vo estudá. Aqui perto tem escola mais a professora só ensina até a quarta série eu já to com 16 ano e tenho que faze o ginázio.

As criança da Maria, da Julinha e do tio Nano estuda nessa escola.

O pai ta com uma roça boa de milho já penduano. Logo nos vamo faze pamonha.

Escreve pra nós Neuza, põe nos cuidado do seu Valdemar Silvino que nós recebe.

O pai mais a mãe só fala em voceis. Eles que que voceis vem pra cá.

Outro dia eu escrevo mais.

Um abraço cheio de saudade da irmã Eva dos Santos.

Rio Branco, 20 de agosto de 2000.

Querida irmã Neuza,

Estamos todos com saúde, graças a Deus. Estou mandando foto do aniversário da Paulinha para você ver como ela está bonita e os meninos estão moços. Paulinha e Everson já estão no $2^{\circ}$ grau.

Neuza, eu sinto muita saudade de você. Agora somos só nos duas. Já perdemos nossos pais, Maria, Tunico e o Zé sumiu.

Se você não pode vir aqui, me escreva, dá notícias.

O pessoal do tio Nano está bem. Virgulino já tem uma colônia dele mesmo. Os meninos mais novos dele estão casados, falta só o Izaias.

Todos aqui de casa mandam lembranças.

Um abraço da mana.

Eva dos Santos Cardoso. 
O conteúdo das cartas coloca em cheque a ideia de que o migrante é um desenraizado, pois em todas elas está expresso um sentimento que somente sobrevive quando se tem raiz. Trata-se da saudade.

\section{Constituição identitária relativas às experiências de uso do solo}

Outras marcas de constituição identitária presentes nesse estudo estão relacionadas ao trabalho agrícola e evidenciam alternativas criadas e recriadas por trabalhadores rurais migrantes do centro-sul e acreanos, relativas às experiências de uso do solo que resultaram em muitos ensinamentos e aprendizagens, mas também em muitos conflitos culturais, muitas vezes travados no puro desconhecimento da história e das tradições de cada povo. Outras vezes, travados no conhecimento, brotado da experiência.

Vejamos, por exemplo, a posição do senhor Vivalde Machado, ex-carreiro no estado de Minas Gerais. "Ah! Meu modo de vive é muito diferente do desse povo. Cumigu, num vai no angu, vai na minhoca. Desde que eu cheguei aqui eu to observano o jeito desse povo e eu, só pela cantiga do carro eu sei o peso que vem dentro" (MACHADO, 2001).

Achamos por bem desmembrar a fala do senhor Vivalde para melhor analisá-la. Na primeira parte, quando o mesmo nos diz: "Meu modo de vive é muito diferente do desse povo", este nos remete a pensar sobre que modos de vida seriam estes tão diferentes dos modos de vida do povo acreano. $\mathrm{Na}$ sequência, o depoente nos diz que essa diferença se dá porque com ele se "num vai no angu, vai na minhoca", o que significa dizer que se uma alternativa socioeconômica, política ou religiosa não der certo, outra será criada.

Outro aspecto que merece ser analisado é a forma precavida, sempre com "o pé atrás", que o migrante olha o viver do povo acreano e vice-versa. Este diz que desde que chegou ao Acre observa o jeito de viver dos acreanos e usa uma expressão metaforizada, baseada em suas experiências enquanto carreiro no estado de Minas Gerais, a partir da qual, a depender do peso da carga que o carro de boi transportava, este fazia um ruído que de longe se podia ouvir para dizer que só pela conversa, pelo comportamento do povo acreano ele já sabe como vivem. Nessa direção, observa-se que o migrante se julga mais esperto, mais empreendedor, o que ao compartilhar experiências com 
o povo acreano o faz mudar, propiciando novas aprendizagens e compreensão dos modos de vida.

Outro migrante entrevistado, o senhor Claudionor dos Santos, trabalhador rural migrante do Paraná, confirma esta assertiva ao relatar como reagiu à sugestão de um colono acreano para que o mesmo não trabalhasse de peão para fazendeiros, alegando que estes pensavam ser possível viver apenas do berro do boi, e que este deveria aprender a caçar, pescar e fazer farinha, podendo inclusive usar a sua casa de farinha: "Olha rapaz: se não dá prá vivê do berro do boi, mas também num vamo vivê do isturro da onça, nem do grito do sapo. Nóis tem que prantá, nós tem que coiê e nóis tem que escoá nossos produto, senão nois num veve, uai" (SANTOS, 1999).

As sugestões e a solidariedade do colono acreano, ao oferecer as instalações e os utensílios de sua rústica fábrica de farinha, naquela oportunidade, soou-lhe como um insulto, pois na estrutura social de trabalho a que estava vinculado, ou seja, a agricultura, não existia a atividade de "farinheiro". Porém, o mesmo entrevistado, trinta anos depois, ao ser interpelado sobre os rumos que os filhos estavam tomando, assim descreve a situação de um deles:

O Valdivino tá casado, tem uma arquera de filho; tudo minino. Mora lá no Iaco, no Posto Serraria. Ele tem uma colonha muito boa. Uma invernadona que é uma beleza; tem um comecinho de criação de gado. Ele é muito trabaiadô. Agora mesmo, há poucos dias eu tive vindo lá da colonha do Zé (outro filho) e ele disse que o Valdivino vendeu umas cento e cinqüenta saca de farinha lá prá comperativa. Fez um contrato lá como a comperativa e ta trabalhando bem ele (SANTOS, 1999).

Conclui-se que produzir farinha também se tornou uma atividade rentável e passível de incorporação em seus modos de trabalho, sem que o desempenho de tal atividade tornasse seu filho mais ou menos trabalhador. No entanto, isto não aconteceu por acaso, de uma hora para a outra, ou passivamente. Foi resultado do compartilhar de experiências e de rompimento com posturas preconceituosas.

Em entrevista realizada com o migrante do Espírito San- 
to, senhor Hélio Tessinari, morador da Vila Capixaba, no estado do Acre, perguntamos-lhe se o mesmo concordava com alguns de seus conterrâneos, que acreano era preguiçoso pelo fato de não ser muito dado à agricultura? E este assim se pronunciou:

Não, eu não concordo qui ele seja priguiçoso. Eu num concordo que dentro da agricultura ele não foi acustumado e ele não tem esse... Ele não pode fazê aquilo que ele num sabi. Agora manda o cara que chamo ele de priguiçoso, joga ele numa istrada di seringa meia-noiti. Vê se ele vai, purque no ivivemu aqui muitas veiz, a gente é caipira, bate dentro duma cidade grande... Mas rapaz, quem mora lá dentru cunhece na hora, o ali, caipira, e tal. Cada um é rei dentru do seu mundo (TESSINARI, 2000).

Ignorar que "cada um é rei dentro do seu mundo" seria algo bastante ingênuo. Contudo, não atentar para as diferentes formas de "reinado", ou seja, para as diversas manifestações de modos de pensar e agir explicitadas por migrantes trabalhadores rurais já não é ingenuidade, mas má fé. Afirmar que o migrante é sempre um desenraizado é um tanto quanto censurável, tendo em vista que desenraizados não têm saudades, não protestam, rendem-se. Supõese que morre, culturalmente falando. E esta não foi a situação ocorrida. Migrantes, trabalhadores rurais trouxeram bens materiais e hábitos nunca abandonados.

O Sr. Césio, engenheiro do INCRA, por ocasião da criação dos Projetos de Assentamentos Dirigidos (PAD’s), descreve a situação em que esses trabalhadores foram recebidos e o que traziam. Segundo ele, alguns traziam vinhos, acolchoados, fogão econômico, máquina de lavar roupa, ferramentas de trabalho tais como: traçador, máquina de moer carne e uma série de outros bens que explicitam seus desejos de continuarem a manter seus modos de vida.

$\mathrm{O}$ dizer de um migrante paranaense morador do PAD Pedro Peixoto, identificado por V., 55 anos, entrevistado por Nascimento, deixa transparecer bem a insatisfação com o viver em um outro lugar. Este, ao comparar e avaliar seu padrão alimentar no Acre e no Paraná diz:

Bão, mais agora em vista que nois chegô, nois ta tudo, tamo de parabéns, graças a Deus. Mas quem ta no Paraná fique quieto no Paraná, que eu falei: "mais vale eu catano soja, quando a 
ceifa cota a soja, do que eu possuí duas, três colonha aqui.” (...) Porque quando eu tava lá, meus fio cumia pão. Minha muié fazia pão, tinha bolacha, tinha trigo, tinha tudo. (...) Meu irmão quando veio troxe doze lata de banha de porco frita e carne. Nóis impatô tempo fritano, inlatano i inlatano aquela fartura. Quando nóis chego, a fartura que nóis vimo foi aquela. Acabô aquela ali, é... Nunca mais cumi margarina, nunca cumi pão. Eu tenho criança que falo óia, aqueles mais velhinho que alembra do pão, mas o mais piqueno falo: "Óia nóis agora temo que cume o pão da terra”. Pão da terra é a macaxera, meus fio considera que é o pão da terra. I é mesmo (NASCIMENTO, 1985. pp. 142 e 143).

O migrante paranaense expressa seu descontentamento através da lembrança da fartura na alimentação. Recente-se do fato dos filhos mais novos não terem acesso a uma alimentação como a de outrora. Por outro lado, pode-se dizer que, neste caso, não houve um desenraizamento e sim um “reenraizamento” (NEVES, 1997, p. 21), pois um pão, o de trigo, foi substituído por um outro, "o pão da terra", a macaxeira. Contudo, percebe-se que o pão de trigo era mais desejado que o "pão da terra", deixando antever a dimensão desse "reinraizamento", que não pode ser visto como um processo "natural", mas envolto em alta complexidade.

\section{Considerações finais}

Pensamos que é necessário que se avalie a natureza das identidades atribuídas ao trabalhador rural. Se é urgente e necessário estudos sobre a "originalidade" das possíveis identidades de trabalhadores rurais migrantes do centro-sul no Acre, é também tão urgente e importante que se reflita sobre os lugares destinados a estes e a constituição de seus modos de vida em determinados ambientes, atentando-se para elementos que devem ser vistos como de contradição, diversidade e complementaridade como forma de procurar compreender as articulações e inter-relações existentes.

A defesa do desenraizamento do migrante é ingênua ou se não ingênua, de má fé. Representa uma tentativa de despolitizá-lo para depois repolitizá-lo através de enquadramentos, modelações, educações e domesticações. Estabelecendo uma identidade fixa para os migrantes, não atentando para a diversidade cultural dos mesmos. Querer apassivar o migrante, atribuindo-lhe pa- 
péis de porta-vozes nos mais diversos setores, sindicatos, escolas, universidades e partidos, por meio das mais variadas linguagens, escrita, televisiva, oral, musical e por meio das mais sutis propostas pedagógicas tem sido um intento constante que tem que ser repelido sob pena de estarmos contribuindo com a reprodução e manutenção de uma história distorcida sobre migrantes do centro-sul no Acre e suas identidades. De igual modo, é preciso reconhecermos que as metáforas utilizadas pelos trabalhadores rurais, sujeitos dessa pesquisa, desempenharam uma função comunicativa importante não apenas no enriquecimento de suas linguagens, mas, no fornecimento de importantes elementos para a análise dos processos identitários desses sujeitos na região acreana.

\title{
BACKGROUNDS AND IDENTITIES OF THE IMMIGRANT RURAL WORKERS FROM CENTRAL AND SOUTHERN BRAZIL INTO ACRE: AN ANALYSIS OF THE METAPHORICAL LANGUAGE
}

\begin{abstract}
Language is one of the main symbols of a culture. Without language it is impossible to define identities and motherlands, to analyse working relationships, processes of integration and segregation of a people, and, mainly, communication between different populations. Despite the current tendency towards the overcoming of national borders, due to the increased communications brought about by globalisation, this overcoming occurs in different ways, depending on social class. The rich have access to the internet, to good movies, books, songs, newspapers, documentaries, photographs, in dialogues regulated by codes based in the native language and, in some cases, in a second language. All that is left to the poor is the language of waters, rivers, of the kenês, and an oral tradition charged with metaphors and puns. This article is an extended version of my master's dissertation and aims at analysing the backgrounds and identities of rural workers migrated into Acre from Central and Southern Brazil. These backgrounds and identities are in turn revealed by metaphors, in a way to reinforce the literary and linguistic value of those for the preservation of memory and identity. This work is based on cultural studies as described by Raymond Williams (1979) and Thompson (1998).
\end{abstract}

KEYWORDS: Immigrant. Rural Workers. Backgrounds and Identities. Metaphorical Language.

\section{Referências}

COSTA, C. A. Mineiro, 74 anos, ex-trabalhador rural, entrevista cedida à autora, rua José 
de Araújo, 61, Bairro Chico Mendes. Rio Branco Acre 2000.

MACHADO, T. M. R. Migrantes Sulistas: Caminhadas, Aprendizados e a Constituição de Modos de Vida na Região Acreana (1977-2000). Recife: UFPE, 2002, Mestrado em História.

MACHADO, Vivalde, ex-trabalhador rural, entrevista cedida à autora, Sena Madureira, dezembro de 2001.

NASCIMENTO, H. W. "Rumo da terra: rumo da liberdade. Um estudo dos migrantes rurais do Sul no Estado do Acre”. Dissertação de Mestrado ,1985.

RODRIGUES, M. A. Riograndense do sul, trabalhador rural, entrevista cedida à autora, Projeto Peixoto, Rio Branco, junho de 2000.

SANTOS, D. F. Experiências de Migração de Trabalhadores Nordestinos-Rondônia 1970-1995. 215 f. Tese (Doutorado em História) - Pontifica Universidade Católica de São Paulo, São Paulo, 1999.

SILVA, J. P. Paranaense, 38 anos, trabalhador rural e professor rural, entrevista cedida à autora, Colônia Santo Antonio, Ramal do Xiburema, Projeto Boa esperança-Sena Madureira Acre. 2001

SOUZA, E. C. Filha de trabalhador rural migrante, entrevista cedida à autora, Rio Branco, Acre, 2000.

TESSINARI, H. Trabalhador rural, capixaba, entrevista cedida à autora, Vila Capixaba -Acre. 2000.

THOMPSON, E. P. Costumes em comum: estudos sobre a cultura popular tradicional. São Paulo: Companhia das Letras, 1998. Introdução: costume e cultura: p. 13-24.

WILLIAMS, R. Marxismo e literatura.Tradução de Waltensir Dutra. Rio de Janeiro: Zahar, 1979 .

ZANOTTTO, M O texto na construção do significado metafórico. In: Cadernos PUC-SP. São Paulo: EDUC 22, 1985.

Data de recebimento: 14/09/2014

Data de aceite: 19/10/2014 